\title{
Related Risk Factors for Pelvic Floor Disorders in Postpartum Women: A Cross-sectional Study
}

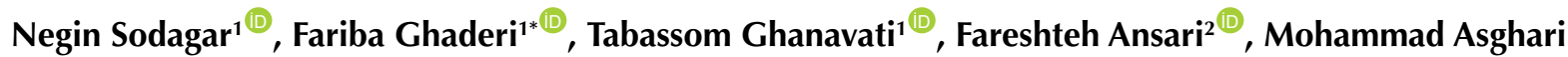 \\ Jafarabadi ${ }^{3}$
}

\begin{abstract}
Objectives: Pelvic floor disorders (PFDs) during pregnancy and after delivery, and related risk factors are still debatable topics for research. Thus, the aim of the present study was to assess the probable risk factors associated with PFDs in Iran.

Materials and Methods: This cross-sectional study was conducted in two state and private hospitals in Tabriz, Iran from the 1st of June to the 31st of August, 2018. The participants were 650 postpartum women, aged between 15 and 47 years six months after delivery. The type of delivery, type of hospital, history of episiotomy and induction, anesthesia, multiparity, the mother's birth age, the infant's weight and head circumference, the mother's weight gain during pregnancy, and a wide variety of probably related risk factors were studied based on the study objective. According to their answer to the questions of PFDs, 147 women responded yes and completed the Pelvic Floor Distress Inventory-20 questionnaire.

Results: Between the investigated risk factors, type of the hospital (OR: 0.27, Cl: 0.126-0.564) and the amount of the mother's weight gain during pregnancy (OR: 1.066, Cl: 1.024-1.109) were significantly associated with PFDs. Finally, the number of PFDs and severity of dysfunctions according to PFDI-20 were higher in state hospitals, and excessive weight gain of the mother during pregnancy was related to the higher incidence of PFDs.

Conclusions: Type of the hospital and the mother's weight gain during pregnancy are the only two related risk factors in this study. This study was the first one to discuss the type of the hospital in such related risk factor studies. Accordingly, it is predictable that better supervision of medical attends in state hospitals is highly important for decreasing the rate of PFDs after delivery.

Keywords: Pelvic floor disorders, Risk factors, Post-partum
\end{abstract}

\section{Introduction}

Pelvic floor muscles and fascia close the pelvic bony outlet and give support to pelvic organs. Pelvic floor muscle contractions play an important role in preventing involuntary loss of the urine or rectal contents (1). Hence, according to Hallock and Handa (2), problems in the structures of the pelvic floor may lead to pelvic floor disorders (PFDs) including urinary incontinence (UI), fecal incontinence (FI), and pelvic organ prolapse (POP). UI is a storage symptom and defined as the complaint of any involuntary loss of urine. FI is defined as any involuntary loss of the fecal material and POP is defined as the symptomatic descent of one or more of the anterior vaginal wall(s), the posterior vaginal wall, and the apex of the vagina (cervix/uterus), or vault (cuff) after hysterectomy (3). It has been reported that $23.7 \%$ of women in the United States experience at least one type of PFDs which doubles in older women (4). Additionally, $76.7 \%$ of Iranian women aged 15-29 years suffer from UI (5) and approximately half of the Iranian women experience some degrees of POP throughout their lives (6).
Although PFDs are rarely life-threatening, the symptoms can reduce the quality of life. If left untreated, they may lead to social isolation, sexual inhibition, job limitations, and potential loss of independence (7). Therefore, PFD is important for determining the predisposing factors according to its high prevalence and bothering nature. Previous studies suggested several factors related to PFDs, including the mode of delivery (7-14), mother age (7$9)$, number of deliveries $(7,8,15,16)$, episiotomy $(9,16)$, the mother's weight $(9,10,14,15,17)$, the mother's weight gain during pregnancy (10), the infant's birth weight and head circumference (18), and education (16). Other related factors were familial positive history of PFDs $(13,17)$, chronic cough, type of anesthesia, and history of induction (13), the number of pregnancies $(13,17)$, history of instrumental or operative vaginal deliveries $(9,10,13,19)$, and smoking $(17,19)$.

However, many of these factors are related to cultural, ecological, and economic features which may vary across different countries. Thus, determining the most important risk factors of PFD in Iranian women is an issue of interest for domestic health services and families. Therefore, 
Key Messages

- Different risk factors from pregnancy and childbirth affect the prevalence of pelvic floor disorders, which is important to study in most developing countries, including Iran.

- This cross-sectional study was performed to investigate a wide range of risk factors during pregnancy and childbirth.

- The rate of maternal weight gain during pregnancy and the type of hospital and to some extent the type of delivery were identified as risk factors for pelvic floor disorders.

- One of the most important factors for the superiority of a private hospital to a teaching hospital is the use of experienced staff in natural childbirth, which minimizes the damage to the pelvic floor. This problem may be minimized by adequate and continuous supervision by gynecology and midwifery professors in teaching hospitals and needs to be considered in the policy-making of specialized women's hospitals.

- Prescribing a proper diet and supporting low-income families can be effective in reducing injuries.

this study sought to determine the main risk factors throughout a wide range of potential factors that may be related to PFD in Iranian women six months after delivery. A "six months" period is the minimum physiological time for the repair of muscles and connective tissues (20). This study is the first one investigating a wide variety of related risk factors and their relationship using a standardized questionnaire in Iran. The results of this study may help anticipate and prevent some PFDs in postpartum women.

\section{Methods and Materials \\ Study Design}

This cross-sectional observational study was performed to determine the probable risk factors for PFDs due to childbirth according to the recommendations of Strengthening the Reporting of Observational Studies in Epidemiology statement (21).

This study was conducted in two state and private hospitals (Alzahra and Shahriar) in Tabriz, Iran from $1^{\text {st }}$ June to $31^{\text {st }}$ August 2018.

\section{Sample Size Calculation}

It was a cross-sectional study and the following formula was used for sample calculation:

$$
N=\frac{Z_{1-\alpha / 2}^{2} P(1-P)}{d^{2}}
$$

where $Z_{1-\alpha / 2}^{2}=1.96, \alpha=0.05$, and the error band was $4 \%$. A total sample size of 648 was obtained by assuming a prevalence of $50 \%$ (to get the maximum sample size) and considering the non-response rate of $8 \%$.

\section{Participants}

A sample of 650 postpartum women aged between 15 and 47 years (mean \pm SD: $28.81 \pm 6.22$ participated in this study. All participants agreed and signed informed consent forms.

\section{Inclusion and Exclusion Criteria}

Women delivered in Alzahra and Shahryar hospitals at Tabriz in least 6 months prior to our data collection and showing a willingness for participation (9) were included in this study. They were excluded if they had urogenital surgeries, mental or cognitive problems (22), pregnancy 6 months after the previous delivery (10), UI, FI, or POP before delivery, and chronic or systemic illnesses such as diabetes, hypertension, and urinary tract infection (9).

\section{Data Collection}

Socio-demographic and personal characteristics were obtained from hospital medical records and telephone interviews with each participant.

Among 650 participants, 147 women answered "yes" to the PFD question and filled out the (PFDI-20) Pelvic Floor Distress Inventory (PFDI) short-form (20) questionnaire (23).

According to the previous study (24), a score of 62 in PFDI-20 was set as the base of having PFDs, and 560 women without PFDs and 90 women with detectable signs of PFDs were identified accordingly (Figure 1).

At the beginning of the interview, the main symptoms and complaints of each PFD category were explained for each participant according to the ICS definition by familiar words, and they were asked "Do you have these signs and symptoms?" If the participant answered "yes", she was categorized as with PFDs and the PFDI-20 questionnaire was completed for her.

A validated Persian version of PFDI was used in our study (25). It has 20 questions divided into three subgroups as follows:

1. Urinary Distress Inventory 6 (UDI-6): Six questions for urinary distress inventory having a score of 0-24;

2. Pelvic Organ Prolapse Distress Inventory 6 (POPDI-6): Six questions for POP distress inventory having a score of $0-24$;

3. Colorectal-Anal Distress Inventory 8 (CRADI-8): Eight questions for colorectal and distress inventory having a score of 0-32.

4. Each distress is expressed in percentage (\%) thus the total score is in the range of $0-300 \%$. The investigated risk factors are listed in Table 1.

Figure 1 shows the number of each group according to PFDI-20 questionnaire results.

\section{Statistical Analysis}

All data were entered into SPSS (version 22, IBM Corp) according to questionnaire records and analyzed accordingly. Descriptive data were described as $\mathrm{n}(\%)$ for categorical variables and as the mean ( \pm standard deviation) for numerical variables and presented in related 


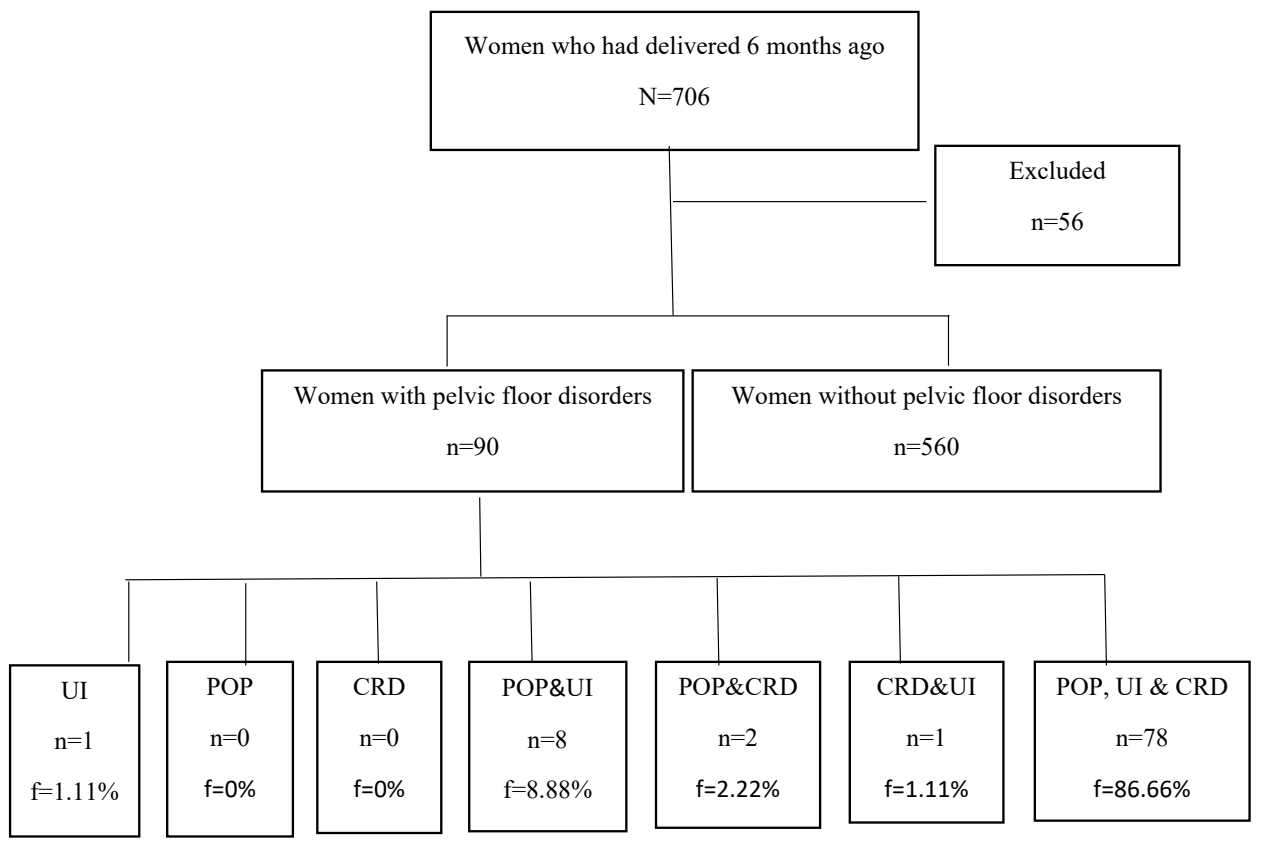

Figure 1. Flow Diagram of the Study. Note. UI: Urinary incontinence; POP: Pelvic organ prolapse; CRD: colorectal dysfunction.

tables. The univariable binary logistic model was used to compare the differences between the groups with and without PFD, followed by a mixed binary logistic model to test the association between independent variables and PFD. All predictor variables with $P<0.2$ were included in the enter/stepwise logistic regression model. The strength of the association was presented as the odds ratio (OR) and a 95\% confidence interval.

\section{Results}

The descriptive statistics of the participants are represented in Tables 2 and 3. Based on the univariate analysis of categorical qualitative and quantitative factors (Tables 2 and 3, respectively), delivery in state hospitals, the amount of the mother's weight gain during pregnancy, and the type of delivery were significantly associated with PFD in post-partum women $(P<0.05)$.
In the multivariate analysis when the aforementioned variables were entered in the multivariate model, only the type of the hospital (odds ratio [OR]: 0.27, CL: 0.1260.564 ) and the amount of the mother's weight gain during pregnancy (OR: 1.066, CL: 1.024-1.109) were significantly associated with PFD. According to PFDI-20, the number of PFDs and severity of dysfunctions were higher in state hospitals, and much weight gain of the mother during pregnancy was related to a higher incidence of PFDs. The results of the logistic multivariate model are summarized in Table 4.

\section{Discussion}

This cross-sectional study investigated the related risk factors in Iranian postpartum women six months after delivery.

The results showed that the mother's much weight

Table 1. Studied Risk Factors for PFDs in Postpartum Women

\begin{tabular}{llll}
\hline \multicolumn{2}{l}{ Studied Risk Factors for PFDs in Postpartum Women } & & \\
\hline 1. & Type of delivery: Vaginal birth or cesarean & 2. & Smoking or alcohol \\
3. & Type of the hospital: Public or state & 4. & Educational level \\
5. & History of episiotomy & 6. & History of multiparity \\
7. & History of induction & 8. & Mother's birth age \\
9. & Anesthesia & 10. & Infant's weight \\
11. & History of surgery in the abdomen, pelvic, or spine & 12. & Infant's head circumference \\
13. & History of back pain & 14. & Mother's weight gain during pregnancy \\
15. & History of chronic coughing & 16. & Number of previous pregnancies \\
17. & Familial positive history of PFDs & 18. & Number of previous deliveries \\
\hline
\end{tabular}

Note. PFD: Pelvic floor disorders. 
Table 2. Descriptive Statistics of Categorical Explanatory Variables Selected for the Multiple Logistic-regression Model of Risk Factors for PFDs Among Study Participants Living in Tabriz, Iran, 2017 ( $\mathrm{n}=650)$

\begin{tabular}{|c|c|c|c|c|c|c|}
\hline Characteristics & All & With PFD (\%) & Without PFD (\%) & OR & $\mathrm{Cl}$ & $P$ Value \\
\hline Hospital type & $650(100.0 \%)$ & $90(100.0 \%)$ & $560(100.0 \%)$ & & & \\
\hline Public & $158(24.3 \%)$ & $82(91.1 \%)$ & $410(73.2 \%)$ & 0.267 & $0.126-0.564$ & 0.001 \\
\hline Private & $492(75.7 \%)$ & $8(8.9 \%)$ & $150(26.8 \%)$ & & & \\
\hline Delivery mode & $650(100.0 \%)$ & $90(100.0 \%)$ & $560(100.0 \%)$ & & & \\
\hline Cesarean & $347(53.4 \%)$ & $31(34.4 \%)$ & $316(56.4 \%)$ & 2.465 & $1.547-3.927$ & 0.000 \\
\hline Vaginal & $303(46.6 \%)$ & $59(65.6 \%)$ & $244(43.6 \%)$ & & & \\
\hline Episiotomy & $303(100.0 \%)$ & $59(100.0 \%)$ & $244(100.0 \%)$ & & & \\
\hline Yes & $238(78.5 \%)$ & 49 (83.1\%) & $189(77.5 \%)$ & 0.701 & $0.333-1.475$ & 0.350 \\
\hline No & $65(21.5 \%)$ & $10(16.9 \%)$ & $55(22.5 \%)$ & & & \\
\hline Induction & $303(100.0 \%)$ & $59(100.0 \%)$ & $244(100.0 \%)$ & & & \\
\hline Yes & $199(65.7 \%)$ & $42(71.2 \%)$ & $157(64.3 \%)$ & 0.730 & $0.392-1.360$ & 0.322 \\
\hline No & $104(34.3 \%)$ & $17(28.8 \%)$ & $87(35.7 \%)$ & & & \\
\hline Anesthesia mode & $347(100.0 \%)$ & $31(100.0 \%)$ & $316(100.0 \%)$ & & & \\
\hline Epidural anesthesia & $247(71.2 \%)$ & $26(83.9 \%)$ & $221(69.9 \%)$ & 2.235 & $0.833-5.997$ & 0.110 \\
\hline General anesthesia & $100(28.8 \%)$ & $5(16.1 \%)$ & 95 (30.1\%) & & & \\
\hline Multiparity history & $650(100.0 \%)$ & $90(100.0 \%)$ & $560(100.0 \%)$ & & & \\
\hline Yes & $16(2.5 \%)$ & $1(1.1 \%)$ & $15(2.7 \%)$ & 2.450 & $320-18.775$ & 0.389 \\
\hline No & $634(97.5 \%)$ & $89(98.9 \%)$ & $545(97.3 \%)$ & & & \\
\hline Coughing history & $650(100.0 \%)$ & $90(100.0 \%)$ & $560(100.0 \%)$ & & & \\
\hline Yes & $35(5.4 \%)$ & $4(4.4 \%)$ & $31(5.5 \%)$ & 1.260 & $0.434-3.648$ & 0.671 \\
\hline No & $615(94.6 \%)$ & $86(95.6 \%)$ & $529(94.5 \%)$ & & & \\
\hline History of surgery in the spine, pelvic, or abdomen & $650(100.0 \%)$ & $90(100.0 \%)$ & $560(100.0 \%)$ & & & \\
\hline Yes & $24(3.7 \%)$ & $3(3.3 \%)$ & $21(3.8 \%)$ & 0.130 & $0.330-3.868$ & 0.846 \\
\hline No & $626(96.3 \%)$ & $87(96.7 \%)$ & $539(96.3 \%)$ & & & \\
\hline History of dysfunctions in mother or sister & $650(100.0 \%)$ & $90(100.0 \%)$ & $560(100.0 \%)$ & & & \\
\hline Yes & $26(4.0 \%)$ & $1(1.1 \%)$ & $25(4.5 \%)$ & 4.159 & $0.557-31.080$ & 0.165 \\
\hline No & $624(96.0 \%)$ & $89(98.9 \%)$ & $535(95.5 \%)$ & & & \\
\hline Alcohol or cigar historya & $650(100.0 \%)$ & $90(100.0 \%)$ & $560(100.0 \%)$ & & & \\
\hline Yes & $0(0)$ & $0(0)$ & $0(0)$ & - & - & - \\
\hline No & $650(100.0 \%)$ & $90(100 \%)$ & $560(100 \%)$ & & & \\
\hline Back pain history & $650(100.0 \%)$ & $90(100.0 \%)$ & $560(100.0 \%)$ & & & \\
\hline Yes & $46(7.1 \%)$ & $5(5.6 \%)$ & $41(7.3 \%)$ & 1.343 & $0.516-3.495$ & 0.546 \\
\hline No & $604(92.9 \%)$ & $85(94.4 \%)$ & $519(92.7 \%)$ & & & \\
\hline Educational level & $650(100 \%)$ & $90(100.0 \%)$ & $560(100.0 \%)$ & 1.024 & $0.787-1.332$ & 0.860 \\
\hline - diploma & $272(41.8 \%)$ & $45(50.0 \%)$ & $227(0.5 \%)$ & - & - & - \\
\hline + diploma and diploma & $237(36.5 \%)$ & $23(25.6 \%)$ & $214(38.2 \%)$ & 0.510 & $0.201-1.292$ & 0.155 \\
\hline Bachelor's & $116(17.8 \%)$ & $15(16.7 \%)$ & $101(118.0 \%)$ & 0.276 & $0.104-0.731$ & 0.010 \\
\hline + bachelor's & $25(3.8 \%)$ & $7(7.8 \%)$ & $18(3.2 \%)$ & 0.382 & $0.137-1.067$ & 0.066 \\
\hline
\end{tabular}

Note. PFDs: Pelvic floor disorders; OR: Odds ratio; $\mathrm{Cl}$ : Confidence interval. ${ }^{\mathrm{a}}$ This variable was not analyzed because no one answered yes in this regard.

Table 3. Definition and Distribution (Mean \pm SD) of Quantitative Explanatory Variables Selected for the Multiple Logistic-regression Model of Risk Factors for PFDs Among Study Participants Living in Tabriz, Iran, 2017 ( $\mathrm{n}=650)$

\begin{tabular}{|c|c|c|c|c|c|c|}
\hline Characteristics & All $($ Mean \pm SD $)$ & With PFD (Mean \pm SD) & Without PFD (Mean \pm SD) & OR & $\mathrm{Cl}$ & $P$ Value \\
\hline Mothers age & $28.81 \pm 6.23(15-47)$ & $29.15 \pm 5.90$ & $28.76 \pm 6.28$ & 0.990 & $0.995-1.026$ & 0.575 \\
\hline Infant's weight & $3.23 \pm 0.43(1.53-4.80)$ & $3.22 \pm 0.41$ & $3.23 \pm 0.43$ & 1.088 & $0.646-1.832$ & 0.752 \\
\hline Infant's head circumference & $34.84 \pm 1.27(31-38)$ & $34.76 \pm 1.25$ & $34.86 \pm 1.28$ & 1.060 & $0.891-1.261$ & 0.509 \\
\hline Mother's weight gain & $10.70 \pm 6.08(0-30)$ & $8.82 \pm 6.02$ & $11 \pm 6.04$ & 1.066 & $1.024-1.109$ & 0.002 \\
\hline Number of previous pregnancies & $0.77 \pm 0.89(0-5)$ & $0.76 \pm 0.90$ & $0.77 \pm 0.89$ & 1.020 & $0.794-1.311$ & 0.876 \\
\hline Number of previous deliveries & $0.71 \pm 0.86(0-4)$ & $0.71 \pm 0.86$ & $0.71 \pm 0.86$ & 1.002 & $0.773-1.299$ & 0.989 \\
\hline
\end{tabular}

Note. SD: Standard deviation; PFDs: Pelvic floor disorders; OR: Odds ratio; Cl: Confidence interval. 
Table 4. Final Mixed Logistic-regression Model for PFDs Among Study Participants Living in Tabriz, Iran, $2017(n=650)$

\begin{tabular}{lccl}
\hline Characteristics & OR & CI & P Value \\
\hline Hospital type & 0.270 & $0.092-0.797$ & 0.018 \\
Mother's weight grow & 1.095 & $1.023-1.173$ & 0.009 \\
\hline
\end{tabular}

Note. Intercept: -0.771; PFDs: Pelvic floor disorders; OR: Odds ratio; $\mathrm{Cl}$ : Confidence interval.

gain during pregnancy in Iranian postpartum women and delivery in a state hospital increase the risk of PFDs. According to univariate analysis, the type of delivery was considerable.

In favor of our hypothesis, the higher risk of PFDs in women was related to delivering in state hospitals. Socioeconomic factors such as lesser costs of health care services in state hospitals may make these hospitals "the choice" for people with lower incomes. Moreover, most of these clients have harder life conditions due to their more stressful physical and psychological work and personal situations. Additionally, the economic situation of those women at younger ages may affect their nutrition and this malnutrition causes their tissue weakness including the pelvic floor tissue. Furthermore, procedures are usually performed by experts in private hospitals, in state ones, which are typically educational centers, and procedures are done by less experienced midwifery students and residents, it is obvious that if medical attends have had better supervision, the quality of service had gotten better.

Therefore, the findings revealed that mothers with higher weight gain during pregnancy were at a higher risk of PFDs. This is in line with the results of some other studies $(10,26)$ while being inconsistent with those of some other studies $(27,28)$. Weight gain in pregnancy is the result of the growing fetus and pregnancy-related organs. However, it is not necessarily in relation to the incidence of UI. Hormonal changes such as relaxin during pregnancy protect muscles and ligaments against the effects of weight gain (29).

The type of delivery was considerable in our study. Supported by several studies, vaginal delivery is one of the most important risk factors for PFD $(9-12,30)$ although few studies have reported that the type of delivery does not play an important role in this regard $(26,31,32)$. Vaginal delivery is the major risk factor for the development of POP, as well as UI and FI as a result of damage to the pelvic floor muscles, nerves, and connective tissues (33). It is also associated with a higher number of levator ani muscle injuries, puborectalis defects, increased bladder neck mobility, and enlargement of the hiatal area (30). Furthermore, parameters such as forceps delivery, vacuum extraction, the prolonged second stage of labor, and perineal tears have been indicated as the most important risk factors for postpartum UI, anal incontinence, and sexual dysfunction $(34,35)$.

\section{Conclusions and Suggestions}

This study was the first one to evaluate type of the hospital. It could be discussable and useful for the health management system to change some related risk factors. The early identification of these risk factors is extremely important to prevent, diagnose, and treat anything that harms a women's physical and emotional health. Generally, the type of the hospital, type of delivery, and mother's weight gain during pregnancy are really important for preventing future problems. It is suggested that future studies be performed with more accurate tools and objective examinations for the type and severity of dysfunctions.

\section{Limitations}

Health status was self-reported or based on medical reports and no medical examination was conducted to diagnose their PFDs. However, a validated questionnaire was used to assess the presence of PFDs.

Our study design was of retrospective cross-sectional type, it would be better if we could do a prospective cohort study.

\section{Authors' Contribution}

NS: Project development and data collection; FG: Project development, data collection, and manuscript writing and editing; TG and FA: Statistical analysis, and manuscript writing and editing; MAJ: Statistical analysis.

\section{Conflict of Interests}

Authors declare that they have no conflict of interests.

\section{Ethical Issues}

This study was approved by the Regional Research Ethics Committee of Tabriz University of Medical Sciences (IR.TBZMED.REC.1397.183).

\section{Financial Support}

This study was funded by Tabriz University of Medical Sciences.

\section{Acknowledgments}

The authors thank all participants, the Physiotherapy Department of Tabriz University of Medical Sciences, and Al-Zahra hospital for their cooperation.

\section{References}

1. Messelink B, Benson T, Berghmans B, et al. Standardization of terminology of pelvic floor muscle function and dysfunction: report from the pelvic floor clinical assessment group of the International Continence Society. Neurourol Urodyn. 2005;24(4):374-380. doi:10.1002/nau.20144

2. Hallock JL, Handa VL. The epidemiology of pelvic floor disorders and childbirth: an update. Obstet Gynecol Clin North Am. 2016;43(1):1-13. doi:10.1016/j.ogc.2015.10.008

3. Abrams P, Andersson KE, Apostolidis A, et al. 6th International Consultation on Incontinence. Recommendations of the International Scientific Committee: evaluation and treatment of urinary incontinence, pelvic organ prolapse and faecal incontinence. Neurourol Urodyn. 2018;37(7):2271-2272. doi:10.1002/nau.23551

4. Nygaard I, Barber MD, Burgio KL, et al. Prevalence of symptomatic pelvic floor disorders in US women. JAMA. 2008;300(11):13111316. doi:10.1001/jama.300.11.1311

5. Sobhgol SS, Charandabee SM. Related factors of urge, stress, mixed 
urinary incontinence and overactive bladder in reproductive age women in Tabriz, Iran: a cross-sectional study. Int Urogynecol J Pelvic Floor Dysfunct. 2008;19(3):367-373. doi:10.1007/s00192007-0437-2

6. Direkvand-Moghadam A, Ghazanfari Z, Sayehmiri K. Predictive factors for pelvic organ prolapse (POP) in Iranian women's: an ordinal logistic approch. J Clin Diagn Res. 2014;8(1):96-99. doi:10.7860/jcdr/2014/7261.3970

7. Krishna Rao B, Nayak SR, Kumar P, Kamath V, Kamath A, Suraj $\mathrm{S}$. Prevalence of pelvic floor dysfunction among married women of Udupi taluk, Karnataka, India. J Womens Health Care. 2015;4(3):236. doi:10.4172/2167-0420.1000236

8. Kepenekci I, Keskinkilic B, Akinsu F, et al. Prevalence of pelvic floor disorders in the female population and the impact of age, mode of delivery, and parity. Dis Colon Rectum. 2011;54(1):8594. doi:10.1007/DCR.0b013e3181fd2356

9. Kokabi R, Yazdanpanah D. Effects of delivery mode and sociodemographic factors on postpartum stress urinary incontinency in primipara women: a prospective cohort study. J Chin Med Assoc. 2017;80(8):498-502. doi:10.1016/j. jcma.2016.06.008

10. $\mathrm{Ng} \mathrm{K}$, Cheung RYK, Lee LL, Chung TKH, Chan SSC. An observational follow-up study on pelvic floor disorders to 3-5 years after delivery. Int Urogynecol J. 2017;28(9):1393-1399. doi:10.1007/s00192-017-3281-z

11. Huser M, Janku P, Hudecek R, et al. Pelvic floor dysfunction after vaginal and cesarean delivery among singleton primiparas. Int J Gynaecol Obstet. 2017;137(2):170-173. doi:10.1002/ijgo.12116

12. Blomquist JL, Muñoz A, Carroll M, Handa VL. Association of delivery mode with pelvic floor disorders after childbirth. JAMA. 2018;320(23):2438-2447. doi:10.1001/jama.2018.18315

13. Czajkowski K, Broś-Konopielko M, Teliga-Czajkowska J. Pregnancy, vaginal delivery, oxytocin and prostaglandin for induction of labour, instrumental vaginal delivery (forceps, VE) and type of anaesthesia and its factual impact on anatomy and function of pelvic floor. Arch Perinatal Med. 2017;23(1):51-58.

14. Mallah F, Tasbihi P, Navali N, Azadi A. Urinary incontinence during pregnancy and postpartum incidence, severity and risk factors in Alzahra and Taleqani hospitals in Tabriz, Iran, 20112012. Int J Womens Health Reprod Sci. 2014;2(3):178-185.

15. Wu JM, Vaughan CP, Goode PS, et al. Prevalence and trends of symptomatic pelvic floor disorders in U.S. women. Obstet Gynecol. 2014;123(1):141-148. doi:10.1097/aog.0000000000000057

16. Dheresa M, Worku A, Oljira L, Mengistie B, Assefa N, Berhane Y. Factors associated with pelvic floor disorders in Kersa district, eastern Ethiopia: a community-based study. Int Urogynecol J. 2019;30(9):1559-1564. doi:10.1007/s00192-018-3776-2

17. Bodner-Adler B, Kimberger O, Laml T, et al. Prevalence and risk factors for pelvic floor disorders during early and late pregnancy in a cohort of Austrian women. Arch Gynecol Obstet. 2019;300(5):1325-1330. doi:10.1007/s00404-019-05311-9

18. Bozkurt M, Yumru AE, Şahin L. Pelvic floor dysfunction, and effects of pregnancy and mode of delivery on pelvic floor. Taiwan J Obstet Gynecol. 2014;53(4):452-458. doi:10.1016/j.tjog.2014.08.001

19. Durnea CM, Khashan AS, Kenny LC, et al. What is to blame for postnatal pelvic floor dysfunction in primiparous women-Prepregnancy or intrapartum risk factors? Eur J Obstet Gynecol Reprod Biol. 2017;214:36-43. doi:10.1016/j.ejogrb.2017.04.036

20. Romano M, Cacciatore A, Giordano R, La Rosa B. Postpartum period: three distinct but continuous phases. J Prenat Med. 2010;4(2):22-25.
21. Cuschieri S. The STROBE guidelines. Saudi J Anaesth. 2019;13(Suppl 1):S31-S34. doi:10.4103/sja.SJA_543_18

22. Zuchelo LTS, de Sousa Santos EF, Dos Santos Figueiredo FW, et al. Pelvic floor disorders in postpartum adolescents in the Western Amazon: a cross-sectional study. Int J Womens Health. 2018;10:477-486. doi:10.2147/ijwh.s169504

23. Barber MD, Walters MD, Bump RC. Short forms of two conditionspecific quality-of-life questionnaires for women with pelvic floor disorders (PFDI-20 and PFIQ-7). Am J Obstet Gynecol. 2005;193(1):103-113. doi:10.1016/j.ajog.2004.12.025

24. Letouzey V, Mercier G, Adjoussou S, Bohoussou E, Mares P, de Tayrac R. Can the PFDI or PFIQ be used to predict outcome in pelvic reconstructive surgery? Prog Urol. 2013;23(11):940-945. doi:10.1016/j.purol.2013.04.010

25. Hakimi S, Hajebrahimi S, Bastani P, Aminian E, Ghana S, Mohammadi M. 208: translation and validation of the pelvic floor distress inventory short form (PFDI-20), Iranian version. BMJ Open. 2017;7(Suppl 1):bmjopen-2016-015415.208. doi:10.1136/ bmjopen-2016-015415.208

26. Barbosa AM, Marini G, Piculo F, Rudge CV, Calderon IM, Rudge MV. Prevalence of urinary incontinence and pelvic floor muscle dysfunction in primiparae two years after cesarean section: crosssectional study. Sao Paulo Med J. 2013;131(2):95-99. doi:10.1590/ s1516-31802013000100019

27. Diez-Itza I, Ibañez L, Arrue M, Paredes J, Murgiondo A, Sarasqueta C. Influence of maternal weight on the new onset of stress urinary incontinence in pregnant women. Int Urogynecol J Pelvic Floor Dysfunct. 2009;20(10):1259-1263. doi:10.1007/s00192-0090923-9

28. Wesnes SL, Hunskaar S, Bo K, Rortveit G. Urinary incontinence and weight change during pregnancy and postpartum: a cohort study. Am J Epidemiol. 2010;172(9):1034-1044. doi:10.1093/aje/ kwq240

29. Kristiansson P, Samuelsson E, von Schoultz B, Svärdsudd K. Reproductive hormones and stress urinary incontinence in pregnancy. Acta Obstet Gynecol Scand. 2001;80(12):1125-1130. doi:10.1034/j.1600-0412.2001.801209.x

30. de Araujo CC, Coelho SA, Stahlschmidt P, Juliato CRT. Does vaginal delivery cause more damage to the pelvic floor than cesarean section as determined by $3 \mathrm{D}$ ultrasound evaluation? a systematic review. Int Urogynecol J. 2018;29(5):639-645. doi:10.1007/s00192-018-3609-3

31. Press JZ, Klein MC, Kaczorowski J, Liston RM, von Dadelszen P. Does cesarean section reduce postpartum urinary incontinence? a systematic review. Birth. 2007;34(3):228-237. doi:10.1111/ j.1523-536X.2007.00175.x

32. Zhu L, Lang J, Liu C, et al. Epidemiological study of urge urinary incontinence and risk factors in China. Int Urogynecol J. 2010;21(5):589-593. doi:10.1007/s00192-009-1041-4

33. Bortolini MA, Drutz HP, Lovatsis D, Alarab M. Vaginal delivery and pelvic floor dysfunction: current evidence and implications for future research. Int Urogynecol J. 2010;21(8):1025-1030. doi:10.1007/s00192-010-1146-9

34. Casey BM, Schaffer JI, Bloom SL, Heartwell SF, Mclntire DD, Leveno KJ. Obstetric antecedents for postpartum pelvic floor dysfunction. Am J Obstet Gynecol. 2005;192(5):1655-1662. doi:10.1016/j.ajog.2004.11.031

35. Serati M, Salvatore S, Khullar V, et al. Prospective study to assess risk factors for pelvic floor dysfunction after delivery. Acta Obstet Gynecol Scand. 2008;87(3):313-318. doi:10.1080/00016340801899008

(C) 2022 The Author(s); This is an open-access article distributed under the terms of the Creative Commons Attribution License (http:// creativecommons.org/licenses/by/4.0), which permits unrestricted use, distribution, and reproduction in any medium, provided the original work is properly cited. 